\title{
Biodiesel fuel production from algal lipids using supercritical methyl acetate (glycerin-free) technology
}

\author{
Prafulla D Patil, ${ }^{\mathrm{a}, \mathrm{b}, \mathrm{c}}$ Harvind Reddy, ${ }^{\mathrm{c}}$ Tapaswy Muppaneni, ${ }^{\mathrm{c}, \mathrm{d}}$ Shuguang Deng ${ }^{\mathrm{*a,c}, \mathrm{d}}$ \\ School of Environmental and Chemical Engineering a \\ Nanchang University \\ Nanchang 330031, Jiangxi, PR China \\ Research \& Development Department ${ }^{\mathrm{b}}$ \\ American Refining Group, Inc. \\ Bradford, PA 16701, U.S.A. \\ Chemical \& Materials Engineering Department ${ }^{c}$ \\ New Mexico State University \\ Las Cruces, NM 88003, U.S.A. \\ School for Engineering of Matter, Transport and Energy ${ }^{\mathrm{d}}$ \\ Arizona State University \\ Tempe, AZ 85287, U.S.A.
}

To be submitted to Fuel, Paper (online)

*Corresponding author: Tel: +1-480-727-7238; Fax: +1-480-727-9231.

E-mail address: shuguang.deng@asu.edu 


\section{ABSTRACT}

Supercritical methyl acetate (SCMA) technology was demonstrated for converting total lipids from Nannochloropsis salina into fatty acid methyl esters (FAMEs) and triacetin (TA). In this non-catalytic process, triacetin is produced instead of glycerin as a side-product during transesterification which is miscible with FAME and can be readily used as biodiesel fuel (BDF). Supercritical carbon-dioxide $\left(\mathrm{SC}-\mathrm{CO}_{2}\right)$, clean and green technology was employed to extract total lipids from algal biomass. The process parameters such as lipid to methyl acetate molar ratio, reaction temperature and reaction time were studied to evaluate their effects on the FAME yield and algal biodiesel fuel yield. Algal lipid characterization and algal biodiesel fuel analysis were carried out using analytical instruments such as FTIR and GC-MS. Thermogravimetric analysis under nitrogen and oxygen environments was performed to examine the thermal and oxidative stability of the algal biodiesel fuel. A micro-elemental analysis (CHNOS) of total algal lipid and biodiesel fuel was performed according to ASTM methods. The fuel properties of algal biodiesel fuel produced were compared with those of the regular diesel and biodiesel American Society for Testing and Materials (ASTM) standards.

Keywords: Supercritical methyl acetate, Algal lipid, Biodiesel fuel, Triacetin, Supercritical carbon-dioxide 


\section{Introduction}

Sustainable development of liquid transportation fuels from biomass is an essential part of diversifying the countries energy portfolio and pushing the economy away from fossil fuel sources [1,2]. Microalgae have been accepted as a potential source for sustainable biofuel production because of their high lipid content, rapid biomass production and ability to reduce the greenhouse gas (GHG) emissions [3,4]. Microalgae accumulate oil as nonpolar storage lipids, such as triacylglycerides (TAGs), hydrocarbons, fatty acids. The photosynthetic and cellular membranes of algae also contain polar lipids, such as glycolipids, phospholipids and sterols.

The value chain associated with the production of algal biodiesel includes algae production strains, cultivation, harvesting, extraction, lipid conversion and up-gradation and lipid extracted algae (LEA) utilization [5]. The lipids naturally created by algae can be converted into biodiesel-a commercialized alternative fuel that's already available. Carbon sequestered via algae farming roughly equals the amount of carbon produced when the fuel is burned, making algae-derived biodiesel carbon neutral. However, biodiesel production from algae is still extensive and expensive process and yet to be commercialized at a greater extend. In addition, a large quantity of glycerol produced during transesterification process as side product leads to oversupply, depreciation in the market prices and big problem in the commercialization of biodiesel $[6,7]$. Therefore, it is necessary to produce an environmentally benign and technically feasible glycerinfree algal biodiesel process.

Many pathways are considered for producing algal biodiesel from algal lipids and biomass to supplement the fossil-based liquid transportation fuels. In situ lipid hydrolysis and supercritical transesterification [8] process was studied for algal biodiesel. The catalytic pyrolysis of green algae was evaluated for hydrocarbon production using H (+) ZSM-5 catalyst [9]. The direct conversion (a 
one-stage method) of dry algal biomass to ester production was implemented using microwave and ultrasound radiation with the aid of a SrO catalyst [10]. The optimization of direct conversion of wet algae to biodiesel under supercritical methanol (SCM) and supercritical ethanol (SCE) conditions was performed [11,12]. The biodiesel production from microalgae oil by non-catalytic transesterification has been studied to evaluate kinetic models and phase behavior [13]. An industrial demonstration unit for non-catalytic biodiesel production from soybean oil, palm oil and waste cooking oil has been in operation since 2009 in China [14]. The artificial neural network modeling and response surface optimization of biodiesel production from crude mahua (Madhuca Indica) oil under supercritical ethanol conditions using $\mathrm{CO}_{2}$ as solvent was studied [15]. The optimization of biodiesel from dried biomass of Schizochytrium limacinum using methanesulfonic acid-DMC was presented as a potential alternative to diesel [16]. All these conversion methods have some limitations such as excess glycerol production, high energy consumption, extensive product separation and low yield recovery.

Converting crude glycerol from biodiesel processes to commercialized grade pure glycerol is a complicated process and requires excess energy and significant cost. The researchers have studied different mechanisms to convert glycerol to biodiesel additives and synthesis glycerin-free catalyzed methods for biodiesel production from oil and fats $[17,18]$. However, these methods are not economically viable due to long reaction time, saponification in catalyzed process due to free fatty acid content, use of toxic solvents and low-grade fuel quality. Therefore, production of glycerin-free biodiesel where fatty acid ester and additives can be produced simultaneously during transesterification reaction seems to be economically viable option for relatively green biodiesel production process. The transesterification reaction between triglycerides and methyl acetate has been evaluated to produce FAMEs and triacetin (additive) as a side product instead of glycerol. 
The conversion of rapeseed oil to fatty acid methyl esters and triacetin under supercritical methyl acetate has been studied to establish the mixture of FAME and TA as a competitive biodiesel fuel [19]. An optimization study using response surface methodology (RSM) approach for glycerinfree biodiesel production from palm oil by supercritical methyl acetate technology has been evaluated to improve the biodiesel quality and minimizes the cost of processing biodiesel additives [20]. This potential technology has several advantages over conventional catalytic processes such as improvement in the biodiesel quality, minimizes the cost of processing biodiesel additives, increases yield of product and simplifies downstream separation and purification. In addition, triacetin miscible with FAME acts as an effective additive helps in enhancing the fuel properties (cetane improver, NOx emission reduction) and engine performance $[21,22]$. However, the research literature on conversion of lipids from algal biomass to biodiesel fuel under supercritical methyl acetate conditions is very limited or possibly not available.

The main objective of this study is to investigate the biodiesel fuel (FAME + Triacetin) production from algal lipids under supercritical methyl acetate conditions. The influence of reaction parameters on the FAME and algal biodiesel fuel yield were evaluated. Analytical results for algal biodiesel fuel obtained from gas chromatography-mass spectrometry (GC-MS), thermogravimetric analysis (TGA) and Fourier transform infrared spectroscopy (FT-IR) are presented. The fuel properties and micro-elemental analysis of algal biodiesel fuel are also discussed in detail.

\section{Materials and methods}

Supercritical Carbon-dioxide $\left(\mathrm{SC}_{-} \mathrm{CO}_{2}\right)$ extracted algal total lipid from dry algal biomass (Nannochloropsis salina sp.) was used for algal biodiesel production in this study. Extra dry 
(+99\%) methyl acetate, sodium sulfate and activated carbon were procured from Acros Organics. All chemicals were at least of A.C.S. grade or better. The supercritical methyl acetate process for algal biodiesel was carried out in the PARR 4593 Micro-reactor with a 4843-controller (Parr Instrument Company, Illinois, USA). Huffman Laboratories, Golden, CO performed the microelemental analysis (CHNOS) on total algal lipid and algal biodiesel fuel samples.

\subsection{Supercritical $\mathrm{CO}_{2}$ extraction of total lipid from algal biomass}

SC-CO ${ }_{2}$ experiments were performed in Waters (TharSFC) SFE-2000F2-1-C50 extraction system with automatic and manual back pressure regulators. The maximum temperature and pressure conditions of the SFE system are $150{ }^{\circ} \mathrm{C}$ and 600 bar respectively. The dry algal biomass was placed in an extraction vessel and pressurized with $\mathrm{CO}_{2}$ to dissolve the sample. Manipulating the temperature and pressure of the fluid can solubilize the material of interest and selectively extract it. Transferred to a fraction collector, the contents were depressurized and the $\mathrm{CO}_{2}$ loses its solvating power causing the desired material to precipitate. The condensed $\mathrm{CO}_{2}$ can be recycled. The optimal conditions for $\mathrm{SC}-\mathrm{CO}_{2}$ process to achieve maximum total algal lipid were reported as: reaction pressure of $340 \mathrm{bar}$, reaction temperature of $80{ }^{\circ} \mathrm{C}$, reaction time of 60 min and $\mathrm{CO}_{2}$ flow-rate of $200 \mathrm{~g} / \mathrm{min}$. The algal total lipid extraction yield was resulted as $25-30 \%$ (on dry basis).

\subsection{Characteristics of total algal lipids}

The chemical composition of Nannochloropsis salina algal biomass was determined as 50$55 \%$ total lipids (\% of dry biomass) by Folch method, 30-32\% proteins and rest carbohydrates. The lipid composition was found as 70-75\% triglycerides (TAG), 8-12\% polar lipids, $2-5 \%$ 
hydrocarbons, and the rest being pigments, free fatty acids, and other various molecules. According to the micro-elemental analysis (CHNOS) report, the carbon and hydrogen percentages were reported as $75.09 \%$ and $11.16 \%$ for total algal lipid. The ratio of O/C and N/C for total algal lipid sample was calculated as 0.129 and $0.005 \%$ respectively. The density and higher heating value of total algal lipid was found to be $0.92 \mathrm{~g} / \mathrm{cc}$ and $38.96 \mathrm{MJ} / \mathrm{kg}$, respectively.

\subsection{Supercritical methyl acetate transesterification}

The transesterification reaction mechanism at supercritical methyl acetate conditions is explained in Fig.1. The reaction proceeds in three stages. Initially, algal lipid (TAGs) reacts with methyl acetate to produce diacetylglyceride and FAME. In a similar way, diacetylglyceride with methyl acetate is transesterified to form methyl ester and monoacetylglyceride, which is converted further to methyl ester and triacetin in the last step. There is possibility of some occurrence of reversible reaction for which excess amount of methyl acetate is needed to shift the equilibrium. The mutual solubility of triglycerides and methyl acetate is relatively high and presents a single-phase reaction site at room temperature [19].

\subsection{Experimental procedure}

The experimental protocol for the supercritical methyl acetate biodiesel production from algal lipids is illustrated in Fig. 2. $5 \mathrm{ml}$ of algal lipid was subjected to a non-catalytic supercritical methyl acetate process in a $100 \mathrm{~mL}$ PARR micro-reactor under a matrix of conditions: reaction temperature of $240,250,280$, and $310^{\circ} \mathrm{C}$; reaction time of $20,30,40$, and $60 \mathrm{~min}$; and methyl acetate to total lipid (molar ratio) of 20,30, 40 and 50. The pressure was kept constant at 100 bar

throughout the reactions with manual back pressure regulator coupled to the PARR reactor. After 
the reaction was completed, the reactor contents were transferred into a $50 \mathrm{~mL}$ round-bottom flask and freed of unreacted methyl acetate, acetic acid (formed during esterification of free fatty acids) and volatiles at a reduced pressure in a rotary evaporator. Hot distilled water was added in small quantity to biodiesel fuel and centrifuged at $3000 \mathrm{rpm}$ for $10 \mathrm{~min}$ to remove the water soluble fractions and by-products. The upper biodiesel fuel layer from centrifuge then filtered through activated carbon using 1.2 $\mu \mathrm{m}$ GFC filters to remove any pigments and entrained impurities and dried with sodium sulfate. The resulting product is analyzed with GC-MS, FTIR and TGA.

\subsection{Analytical methods}

The algal biodiesel samples were analyzed by a gas chromatography-mass spectrometry (GCMS) system incorporated with an Agilent 5975 C MSD (Triple-Axis Detector) and an Agilent 7890 A GC equipped with a capillary column (DB-23, $60 \mathrm{~m} \times 250 \mu \mathrm{m} \times 0.15 \mu \mathrm{m}$ nominal). The external standard calibration method was implemented for the final product quantification. FAME yield based on the total lipid is defined as ratio of weight of FAMEs detected by GC-MS to the weight of total lipid. Biodiesel fuel (BDF) yield is defined as the ratio of the combined weight of FAME and triacetin (as biodiesel fuel) measured to the weight of total lipid. The IR spectra were obtained using a Perkin Elmer Spectrum 400 FT-IR/FT-NIR spectrometer. The samples placed on $\mathrm{KBr}$ IR cards and scanned at room temperature $\left(25 \pm 2^{\circ} \mathrm{C}\right)$ in the mid-infrared region (4000-400 $\mathrm{cm}^{-1}$ ). Five spectra were taken for each sample, at 5 scans and $4 \mathrm{~cm}^{-1}$ spectral resolution. Thermogravimetric analysis (TGA) of algal biodiesel fuel samples was performed using Perkin Elmer Pyris 1 TGA. The samples were heated from 25 to $1000{ }^{\circ} \mathrm{C}$ at constant heating rate of 10 ${ }^{\circ} \mathrm{C} / \mathrm{min}$ in an atmosphere of nitrogen and oxygen at a constant purge rate of $20 \mathrm{~mL} / \mathrm{min}$ at the pan. The micro-elemental analysis (CHNOS) of total algal lipid and biodiesel fuel samples was 
performed according to ASTM testing methods at Huffman Laboratories and preliminary results were presented. The samples were warmed at $120^{\circ} \mathrm{F}$ for 20 minutes prior to sampling. Hydrogen $\left(\mathrm{H}_{2}\right)$ and Oxygen $\left(\mathrm{O}_{2}\right)$ as reported include contributions from any water that may be contained in the sample at the time of analysis. CHNOS analysis of samples were performed using various instruments: Carbon $(\mathrm{C})$ and Hydrogen $\left(\mathrm{H}_{2}\right)$ were determined using a custom built analyzer which uses coulometric detection; Oxygen $\left(\mathrm{O}_{2}\right)$ was determined on a Leco RO-478 oxygen analyzer; nitrogen on a flash EA 1112 series nitrogen $\left(\mathrm{N}_{2}\right)$ analyzer while sulfur (S) on a Leco Model S144DR sulfur analyzer. The inorganic content of ash (A) was calculated by difference, A (wt.\%) $=100-(\mathrm{C}+\mathrm{H}+\mathrm{O}+\mathrm{S}+\mathrm{N})(\mathrm{wt} . \%)$.

The higher heating value (HHV) of total algal lipid and algal biodiesel was calculated by the Dulong's formula [23,24] on the basis of their elemental compositions.

$$
\mathrm{HHV}(\mathrm{MJ} / \mathrm{kg})=0.3383 \mathrm{C}+1.422(\mathrm{H}-\mathrm{O} / 8)
$$

Where $\mathrm{C}, \mathrm{H}$ and $\mathrm{O}$ are the weight percentages of carbon, hydrogen and oxygen in the samples, respectively.

\section{Results and discussion}

\subsection{Influence of process parameters on yield}

To study the effect of methyl acetate to total lipid to on the yield of FAME and biodiesel fuel, the methyl acetate to total lipid (molar ratio) was varied from 20:1 to 50:1 (Fig. 3). The reaction temperature, reaction pressure and reaction time was kept constant at $310{ }^{\circ} \mathrm{C}, 100$ bar and $60 \mathrm{~min}$ respectively throughout the reaction. $5 \mathrm{ml}$ of total algal lipid was processed in supercritical methyl acetate (SCMA) process. As there is possibility of some generation of reversible reaction, higher solvent to oil ratio (vol./vol.) is required to shift the equilibrium toward the product side in noncatalytic supercritical condition [25]. In addition, to nullify the effect of acetic acid (corrosive at 
high concentration) produced during esterification of free fatty acids, more amount of methyl acetate is warranted. It was observed that the yield of FAME and algal biodiesel fuel was recorded around $26 \%$ and $32 \%$ respectively at molar ratio of 20:1. The product yield was started increasing at higher molar ratio and achieved a maximum FAME and biodiesel fuel at 40 (mol/mol), $310^{\circ} \mathrm{C}$ and $60 \mathrm{~min}$ of reaction time. In this non-catalytic reaction system, methyl acetate acts as both a 'solvent' and reactant and/or acid catalyst for esterification as well as transesterification reactions in the algal biodiesel production. It was observed that the yields were started declining after $40(\mathrm{~mol} / \mathrm{mol})$ perhaps because of limitation of reaction equilibrium and excess un-reacted methyl acetate started to interfere in the phase of FAME and triacetin imposed separation problem and resulted in lower yield. Use of excess methyl acetate makes the separation of final product energy intensive. A similar trend was observed while transesterification of palm oil under supercritical methyl acetate conditions [20].

The yield of FAME and biodiesel fuel increases proportionally with reaction temperature favored by increased reaction rate and mutual solubility (Fig. 4). The effect of reaction temperature on the product yields was studied at different temperatures varied from $240{ }^{\circ} \mathrm{C}$ to 310 ${ }^{\circ} \mathrm{C}$ with methyl acetate to total lipid molar ratio of $40: 1$, reaction pressure of 100 bar for 60 min of reaction time. The maximum operating temperature allowed by PARR micro-reactor in this reaction system is up to $320^{\circ} \mathrm{C}$ that puts limitation on increasing the reaction temperature and thus reaction rate. As shown in Fig. 4, at low reaction temperature of $240{ }^{\circ} \mathrm{C}$, the yields were found to be low as the temperature was just above the critical temperature of methyl acetate and not sufficient to enhance the rate in this non-catalytic reaction system. The critical temperature and pressure of methyl acetate is reported as $233.7^{\circ} \mathrm{C}$ and 45.9 bar, respectively. The high algal biodiesel fuel yield of $80 \%$ and FAME yield of $72 \%$ was obtained at reaction temperature of 310 
${ }^{\circ} \mathrm{C}$. The optimized temperature to achieve maximum yield in the transesterification reaction of wet algal biomass to fatty acid methyl ester under supercritical methanol (SCM) conditions was found around $255^{\circ} \mathrm{C}$ [26]. It has been found that methyl acetate has lower reactivity than methanol with triglycerides (TG) during transesterification reaction and requires extreme operating conditions to obtain maximum biodiesel fuel yield [27]. This indicates that the SCMA process should be carried out at higher temperature than SCM process to increase the mutual solubility, enhance the reaction rate and accelerates the yield of the algal biodiesel fuel.

The algal biodiesel fuel (FAME + Triacetin) yield of $80 \%$ at reaction temperature of $310{ }^{\circ} \mathrm{C}$ is possible along with transesterification of triglycerides due to two vital factors which are firstly, other fractions of total algal lipids include hydrocarbons, esters and polar lipids can possibly converted to FAME at supercritical conditions. Secondly, the free fatty acids (FFAs) present in total algal lipids can easily undergo esterification to yield FAME at lower reaction temperature as studied by the researcher [19]. In addition to that, FFA and acetic acid produced (during esterification) also provides acid catalysis effect in increasing the FAME yield. Acetic acid was removed gently from the reaction system by vacuum distillation due to the difference in the boiling points (FAME; over $180^{\circ} \mathrm{C}$; acetic acid; $118^{\circ} \mathrm{C}$ ). At higher temperature than $310^{\circ} \mathrm{C}$ may trigger the slow degradation of poly-unsaturated fatty acids (PUFAs) through isomerization [28] and/or autoxidation of the reactive intermediates (organic substrates) restrict in achieving maximum algal biodiesel yield.

Fig. 5 shows the influence of the reaction time varies from 20 to 60 min with methyl acetate to total lipid molar ratio of $40: 1$, reaction temperature of $310^{\circ} \mathrm{C}$ and reaction pressure of 100 bar. The yields were observed to be at reaction time of $20 \mathrm{~min}$. The shorter reaction times do not provide sufficient interaction of the reactant mixture in non-catalytic algal biodiesel synthesis. 
Increasing in the reaction time accelerates the yield of biodiesel fuel as prolonging the duration allows higher reactivity between reactants. In addition, it also allows the reaction to reach equilibrium and stability which is vital if the reversible reaction occurs [20]. The maximum yields were achieved at 60 min of reaction time. Based on the experimental analysis, the conditions for this SCMA glycerin-free process to achieve high algal biodiesel fuel yield and FAME yield are reported as: reaction temperature of $310{ }^{\circ} \mathrm{C}$, reaction pressure of 100 bar and methyl acetate to total lipid molar ratio of 40:1at reaction time of 60 min. Higher temperature and pressure than reported could be helpful (by controlling PUFA degradation and limiting reversible reaction) in enhancing the reaction rate coupled with increased mutual solubility to yield maximum biodiesel fuel yield. However, achieving these higher operating conditions were limited by reactor set-up.

\subsection{Analysis of algal lipid}

The fatty acid methyl esters and triacetin composition (wt. \%) in algal biodiesel fuel (BDF) detected by GC-MS analysis were (Fig.S2): Methyl tetradecanoate (C14), 2.53\%; Triacetin $\left(\mathrm{C}_{9} \mathrm{H}_{14} \mathrm{O}_{6}\right), 3.6 \%$; Hexadecanoic acid methyl ester (C16:0), 38.1\%; 9-Hexadecenoic acid methyl ester (C16:1), 30.2\%; Octadecanoic acid methyl ester (C18:0), 1.11\%; 9-Octadecenoic acid methyl ester (C18:1), 18.05\% ; 9,12-Octadecadienoic acid methyl ester (C18:2), 1.7\%; 9,12,15Octadecatrienoic acid methyl ester (C18:3), 1.8\%; 5,8,11,14,17-eicosapentaenoatic acid methyl ester (C20:5) 2.5\%. Palmitic acid, C16:0 and palmitoleic acid, C16:1 methyl esters contribute around $71.15 \%$ of total fatty acid methyl esters. The percentages of saturated fatty acid methyl esters and unsaturated fatty acid methyl esters were calculated to $41.74 \%$ and $54.25 \%$, respectively. The ratio of sums of unsaturated to saturated fatty acids was calculated to be 1.29. The low ratio indicate the suitability of Nannochloropsis salina as a potential source for the 
production of biodiesel fuel and ensure better cetane number and increased fuel stability of biodiesel fuel. In addition, triacetin (boiling point: $259^{\circ} \mathrm{C}$ ) produced during transesterification acts as an additive to reduce NOx emission to further extend. From the GC-MS, it was observed that the algal biodiesel fuel also contains fatty alcohols, aldehydes, sterols and vitamins in minor quantities. In a major research concern, high percentage of EPA, i.e. C20:5n3 is not acceptable in algal methyl ester in terms of fuel properties (e.g. oxidative stability, ignition quality pollutant formation) and can be reduced by partial catalytic hydrogenation of the oil.

The various absorption peaks of algal biodiesel fuel (FAME+ Triacetin) with their group attribution, vibration type and absorption intensity were listed in Table 1 . The strong methyl ester peak around $1745 \mathrm{~cm}^{-1}(\mathrm{C}=\mathrm{O}$ ester $)$ and $1167 \mathrm{~cm}^{-1}(\mathrm{C}-\mathrm{O}$ ester $)$ are clearly present in the spectra for algal biodiesel fuel. Methylene $\left(-\mathrm{CH}_{2}\right)$ and methyl groups $\left(-\mathrm{CH}_{3}\right)$ were identified and shows characteristic bending absorption of approximately at $1464-1375 \mathrm{~cm}^{-1}$. The band corresponding to the $\mathrm{vC}(=\mathrm{O})-\mathrm{O}$ vibration shows a peak around $1227-1230 \mathrm{~cm}^{-1}$ in algal biodiesel fuel and is one of the confirmations of the conversion of algal lipid to methyl esters. In addition, some other absorbance peaks appearing at the band of $650-900 \mathrm{~cm}^{-1}$ are ascribed to the $\mathrm{C}-\mathrm{H}$ bending vibrations from aromatics.

\subsection{Elemental analysis of algal biodiesel fuel}

The micro-elemental analysis (CHNOS) of SCMA algal biodiesel fuel is shown in Table 2. The carbon and hydrogen percentages were reported as $75.34 \%$ and $11.3 \%$ for algal biodiesel fuel. Higher ratio of $\mathrm{H} / \mathrm{C}$ of fuel sample (1.8) indicates better fuel, combustion and physicochemical properties. The ratio of $\mathrm{O} / \mathrm{C}$ and N/C for biodiesel fuel sample was calculated as 0.132 and $0.0005 \%$ respectively. 
Bio-oil/crude cannot be directly applied as a high-grade fuel because of its inferior properties, such as high water and oxygen contents, high acidity, high percentages of heteroatoms, low heating value, high viscosity and partial volatility. Thus, it is necessary to upgrade or convert biooil through transesterification, hydrogenation, catalytic upgrading and steam reforming to produce a high-grade liquid fuel that can be used in engines $[29,30]$. The heteroatom contamination of $\mathrm{N}$ : 0.46\% and S: $0.09 \%$ in total lipid was reduced to N: $0.05 \%$ and S: $0.02 \%$ in SCMA algal biodiesel fuel. The heteroatom percentage of oxygen $(\% \mathrm{O})$ in algal biodiesel fuel was increased compared to total lipid because of the presence of additional oxygen in the molecular structure of triacetin $\left(\mathrm{C}_{9} \mathrm{H}_{14} \mathrm{O}_{6}\right)$ miscible with FAME. In addition, hydrogen and oxygen as reported include contributions from any water that may be contained in the sample at the time of analysis. The increased amount of oxygen in algal biodiesel fuel possibly help in complete combustion of fuel and reducing the soot production [31]. The presence of oxygen as a polar compound in the biodiesel fuel attribute in enhancing its lubricity, wetting and soluble properties [32]. The lower percentages of $\mathrm{N}$ and $\mathrm{S}$ in algal biodiesel fuel indicates that most of the nitrogen and sulfur compounds present in the total algal lipid (mainly in the phospholipids and glycolipids) are likely removed during purification stage of biodiesel fuel following transesterification reaction as water soluble fraction and/or by-products. This reported very low content of heteroatoms $(\mathrm{N}, \mathrm{S})$ in algal biodiesel fuel may be helpful in providing color stability, better engine performance and controlling corrosion problem.

\subsection{Fuel Properties of biodiesel fuel (BDF)}

The fuel properties of algal biodiesel fuel (BDF) from total algal lipid with testing methods are given in Table 3. The cetane number was estimated as $52-55$ and found to be higher than 
ASTM biodiesel standards [33]. A higher cetane number of algal biodiesel fuel which is mixture of FAME and triacetin indicates a good ignition quality of fuel. Biodiesel that uses triacetin as additive, which is a cetane improver, has resulted in lower NOx emissions to a reasonable extent [22]. In addition, triacetin is a good anti-knocking gasoline additive suppresses engine knocking, improve the performance and reduce tail pipe emissions [21]. Higher heating value (HHV) is a measure of the energy content of the fuel which determines its suitability as an alternative to regular diesel. The HHV of algal biodiesel fuel (BDF) was found to be $39.2 \mathrm{MJ} / \mathrm{kg}$, which is almost $93.33 \%$ of the calorific value of regular diesel $(42 \mathrm{MJ} / \mathrm{kg}$ ). The lower HHV of biodiesel fuel is because of the additional oxygen contributed from triacetin molecule present in the biodiesel fuel, which is also confirmed by micro-elemental analysis. The pour point of biodiesel fuel was found to be between -11 and $-8{ }^{\circ} \mathrm{C}$, indicating good compatibility of fuel in the cold season. Algal biodiesel fuel has very low sulfur content and possesses natural lubricity components that will help to increase fuel (regular diesel) lubricity when it is blended with biodiesel fuel.

\subsection{Thermal stability of algal biodiesel fuel}

The thermogravimetric plot in linear and differential form for biodiesel fuel (BDF) under nitrogen environment is shown in Fig S1 (A). Thermal stability of algal biodiesel fuel from total lipid was determined from onset temperature of thermal degradation under nitrogen atmosphere. The onset temperature for volatilization of algal biodiesel fuel was recorded around $130-140{ }^{\circ} \mathrm{C}$. The sample weight loss (thermal degradation) of $10 \%, 50 \%$ and $90 \%$ to the initial weight was recorded at the temperature of 205,300 and $475{ }^{\circ} \mathrm{C}$, respectively. These temperatures can be

referred as 'distillation temperature' of the biodiesel fuel (BDF). TGA-DTA curve of biodiesel 
fuel (FAME + Triacetin) sample represent the three stage decomposition at 120-220, 220-450 and $450-950^{\circ} \mathrm{C}$.

Oxidative stability is the quality indicative parameter for algal biodiesel fuel. Fig. S1 (B) shows the oxidative degradation TGA-DTA profile of algal biodiesel fuel under oxygen atmosphere. The onset temperature of oxidative decomposition for algal BDF recorded as 115$125^{\circ} \mathrm{C}$. The oxidative degradation temperatures corresponding to the sample weight loss of $10 \%$, $50 \%$ and $90 \%$ to the initial weight was recorded at 173,271 and $456{ }^{\circ} \mathrm{C}$, respectively. The results revealed that algal biodiesel fuel under $\mathrm{O}_{2}$ is almost as stable as in the $\mathrm{N}_{2}$ atmosphere indicating good oxidation stability of fuel. From DTA curve for algal biodiesel fuel Fig. S1 (B), four steps were observed; being the first one related to oxidation and decomposition reactions and the last steps related to the subsequent polymerization and combustion reactions.

\section{Conclusions}

Supercritical methyl acetate process was demonstrated as an effective technique for production of algal biodiesel fuel which is mixture of fatty acid methyl ester (FAME) and triacetin (TA). This glycerin-free and non-catalytic transesterification process is more economical and environmentally friendly as it greatly simplifies the downstream process of separation and purification. The fuel properties of algal biodiesel comparable with regular diesel and ensures better ignition quality and engine performance. This supercritical methyl acetate process has the potential to provide an energy-efficient and economical route for algal biodiesel production. However further studies on reaction kinetics and thermodynamics, process economics, and energy recovery are needed for a sustainable production of algal biofuel and development of high value co-products. 


\section{Acknowledgements}

We gratefully acknowledge the financial supports from US Department of Energy (DEEE0003046), US Air Force Research Laboratory (FA8650-11-C-2127) and National Science Foundation (EEC-1028968), and NMSU College of Engineering "Freeport MacMoran Water Lab" for the analytical support.

\section{Supporting Information}

Fig.S1(A): Thermogravimetric (TGA-DTA) analysis of algal biodiesel fuel under nitrogen environment. Fig.S1(B): Thermogravimetric (TGA-DTA) analysis of algal biodiesel fuel under oxygen environment. Fig.S2: GC-MS Chromatograph of algal biodiesel fuel (FAME+ Triacetin) with Retention Time.

\section{References}

[1] Demirbas A. Global renewable energy projections. Energy Sources Part B 2009; 4: 212224.

[2] Klass D. Biomass for Renewable Energy, Fuel and Chemicals. Academic Press 1998, San Diego.

[3] Hossain AB, Salleh A. Biodiesel Fuel Production from Algae as Renewable Energy. Am. J. Biochem. Biotechnol 2008; 4: 250- 254.

[4] Sheehan J, Dunahay T, Benemann J, Roessler P. A Look Back at the U.S. Department of Energy’s Aquatic Species Program-Biodiesel from algae 1998, NREL.

[5] Chisti Y. Biodiesel from microalgae. Biotechnol. Adv. 2007; 25: 294-306.

[6] Galan, MI, Bonet J, Sire R, Reneaume JM, Plesu AE. From residual to useful oil: revalorization of glycerine from the biodiesel synthesis. Bioresource Technology 2009; 100: $3775-3778$. 
[7] Johnson DT, Taconi KA. The glycerin glut: options for the value-added conversion of crude glycerol resulting from biodiesel production. Environmental Progress 2007; 26: $338-348$.

[8] Levine RB, Pinnarat T, Savage PE. Biodiesel production from wet algal biomass through in situ lipid hydrolysis and super-critical transesterification. Energy Fuels 2010; 24: 52355243.

[9] Thangalazhy-Gopakumar S, Adhikari S, Chattanathan SA, Gupta RB. Catalytic pyrolysis of green algae for hydrocarbon production using $\mathrm{H}(+) \mathrm{ZSM}-5$ catalyst. Bioresource Technology 2012; 118:150-157.

[10] Koberg M, Cohen M, Ben-Amotz A, Gedanken A. Biodiesel production directly from the microalgae biomass of Nannochloropsis by microwave and ultrasound radiation. Bioresour. Technol. 2011; $102:$ 4265-4269.

[11] Patil P, Veera G, Mannarswamy A, Deng S, Cooke P, Munson-McGee S, Rhodes I, Lammers P, Khandan N. Optimization of direct conversion of wet algae to biodiesel under supercritical methanol conditions. Bioresour. Technol. 2011; 102: 118-122.

[12] Reddy H, Muppaneni T, Patil P, Ponnusamy S, Cooke P, Schuab T, Deng S. Direct conversion of wet algae to crude biodiesel under supercritical ethanol conditions. Fuel 2014;

115: 720-726. 
[13] Liu J, Lin, R, Nan Y, Tavlarides LL. Production of biodiesel from microalgae oil (Chlorella

protothecoides) by non-catalytic transesterification: Evaluation of reaction kinetic models and phase behavior. The Jour. Of Supercritical Fluids 2015; 99: 38-50.

[14] Du Z, Tang Z, Wang H, Zeng J, Chen Y, Min E. Research and development of a subcritical

methanol alcoholysis process for producing biodiesel using waste oils and fats. Chinese J.

Catalysis 2013; 34:101-115.

[15] Sarve AN, Verma MN, Sonawane SS. Response surface optimization and artificial neural

network modeling of biodiesel production from crude mahua (Madhuca indica) oil under supercritical ethanol conditions using $\mathrm{CO}_{2}$ as cosolvent. RSC Adv. 2015; 5- 6970269713.

[16] Panchal BM, Padul MV, Kachole MS. Optimization of biodiesel from dried biomass of Schizochytrium limacinum using methanesulfonic acid-DMC. Renewable Energy 2016; 86: 1069-1074.

[17] García E, Laca M, Pérez E, Garrido A, Peinado J. New class of acetal derived from glycerin as a biodiesel fuel component. Energy \& Fuels 2008 ; 22 : 4274-4280.

[18] Fabbri D, Bevoni V, Notari M, Rivetti F. Properties of a potential biofuel obtained from soybean oil by transesterification with dimethyl carbonate. Fuel 2007; 86 : 690-697.

[19] Saka S, Isayama Y. A new process for catalyst-free production of biodiesel using supercritical methyl acetate. Fuel 2009; 88 :1307-1313. 
[20] Tan KT, Lee KT, Mohamed AR. A glycerol-free process to produce biodiesel by supercritical

methyl acetate technology: An optimization study via Response Surface Methodology.

Bioresour. Technol. 2010 ; 101, 965-969.

[21] Mufrodi Z, Sutijan R, Budiman A. Chemical kinetics for synthesis of triacetin from biodiesel byproduct. Int. J. Chem. 2012 ; 4: 100-107.

[22] Rao PV, Rao BVA. Effect of adding triacetin additive with Coconut oil methyl ester (COME)

in performance and emission characteristics of DI diesel engine. Int. J. of Thermal Tech. 2011; $1: 100-106$.

[23] BrownT, Duan P, Savage PE. Hydrothermal Liquefaction and Gasification of Microalga Nannochloropsis sp. Energy Fuels 2010; 24 : 3639-3646.

[24] Zhou D, Zhang L, Zhang S, Fu H, Chen J. Hydrothermal liquefaction of macroalgae Enteromorpha prolifera to bio-oil. Energy and Fuels 2010. 24, 4054-4061.

[25] Song ES, Lim JW, Lee HS, Lee YW. Transesterification of RBD palm oil using supercritical methanol. J. Supercrit. Fluids 2008; 44: 356-363.

[26] Patil P, Veera G, Mannarswamy A, Deng S, Cooke P, Munson-McGee S, Rhodes I, Lammers P, Khandan N. Comparison of direct transesterification of algal biomass under supercritical methanol and microwave irradiation conditions. Fuel $2012 ; 97$ : 822-831.

[27] Saka S, Kusdiana D. Biodiesel fuel from rapeseed oil as prepared in supercritical methanol.

Fuel 2001; 80: 225-231. 
[28] Imahara H, Minami E, Hari S, Saka S. Thermal stability of biodiesel in supercritical methanol. Fuel 2008; 87:1-6.

[29] Bridgwater AV. Production of high grade fuels and chemicals from catalytic pyrolysis of biomass. Catalysis Today 1996; 29: 285-295.

[30] Czernik S, Bridgwater AV. Overview of applications of biomass fast pyrolysis oil. Energy \& Fuels 2004 ; 18: 590-598.

[31] Zhang J, Jing W, Roberts W, Fang T. Effects of ambient oxygen concentration on biodiesel and diesel spray combustion under simulated engine conditions. Energy 2013; 57: 722732.

[32] Hazrat MA, Rasul M. G., Khan MMK. Lubricity Improvement of the Ultra-low Sulfur Diesel Fuel with the Biodiesel. Energy Procedia 2015 ; 75: $111-117$.

[33] ASTM. American standards for testing of materials 2008 [D 189-01, D 240-02, D 405296, D 445-03, D 482-74, D 5555-95, D 6751-02.

\section{List of Figures}

Fig.1. Transesterification reaction mechanism of algal lipid at supercritical methyl acetate condition. 
Fig. 2. Experimental protocol for supercritical methyl acetate process for algal biodiesel fuel production.

Fig. 3. The influence of methyl acetate to total lipid (mol/mol) ratio on fatty acid methyl ester (FAME) and algal biodiesel fuel (BDF) yield.

Fig. 4 The influence of reaction temperature on fatty acid methyl ester (FAME) and algal biodiesel fuel (BDF) yield.

Fig. 5. The influence of reaction time on fatty acid methyl ester (FAME) and algal biodiesel fuel (BDF) yield. 


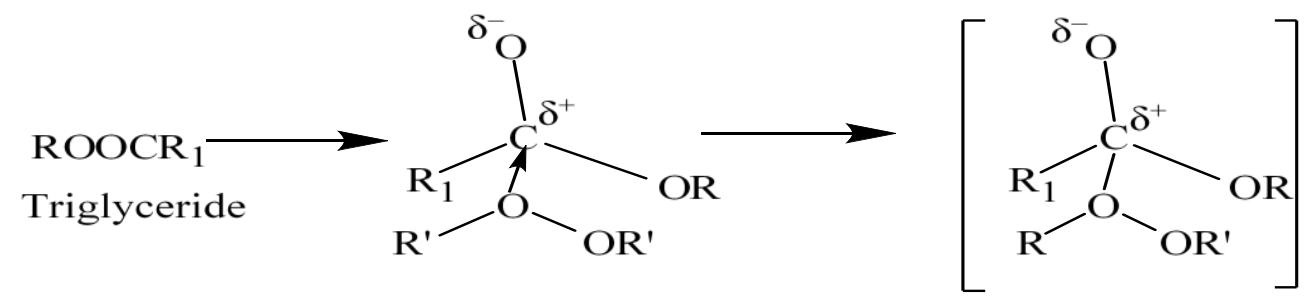

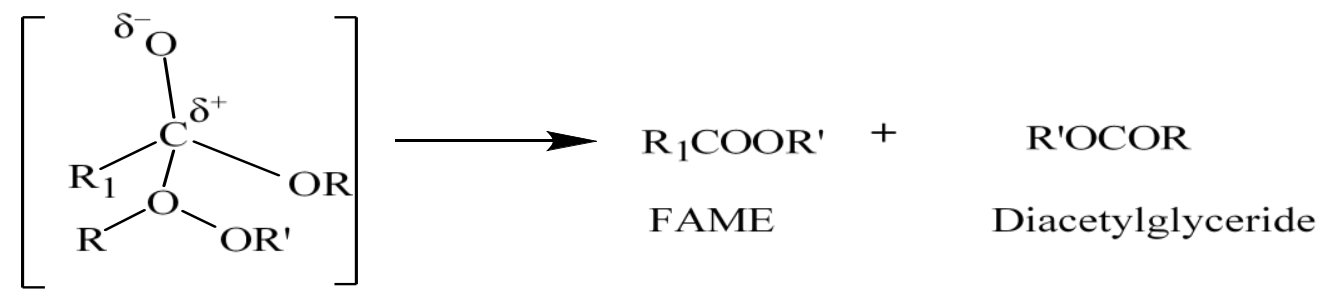

$\mathrm{R}_{1}$ : Long Chain Hydrocarbon, R': Alkyl Group, R: Glycerol Group

Fig. 1

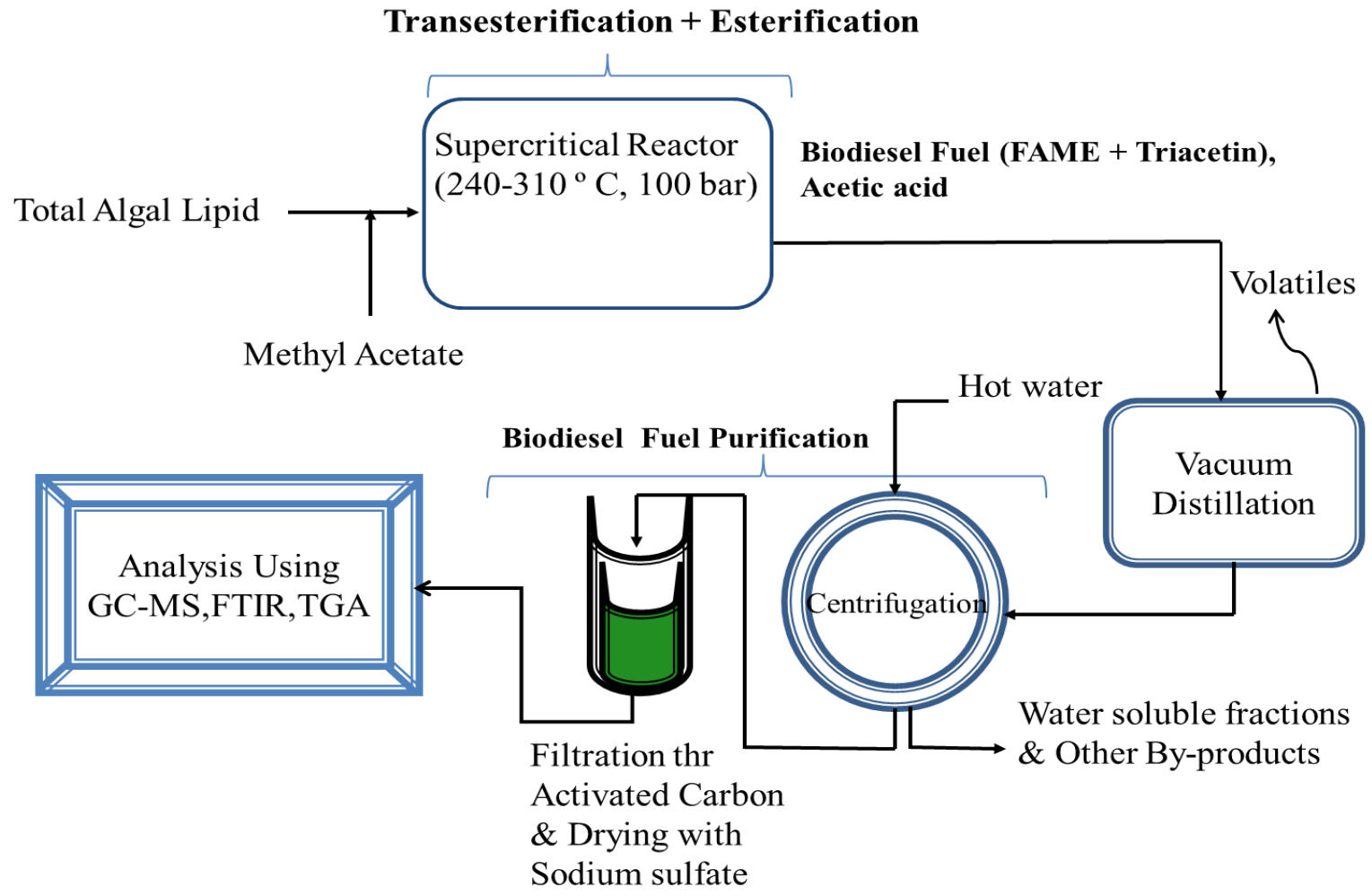

Fig. 2 


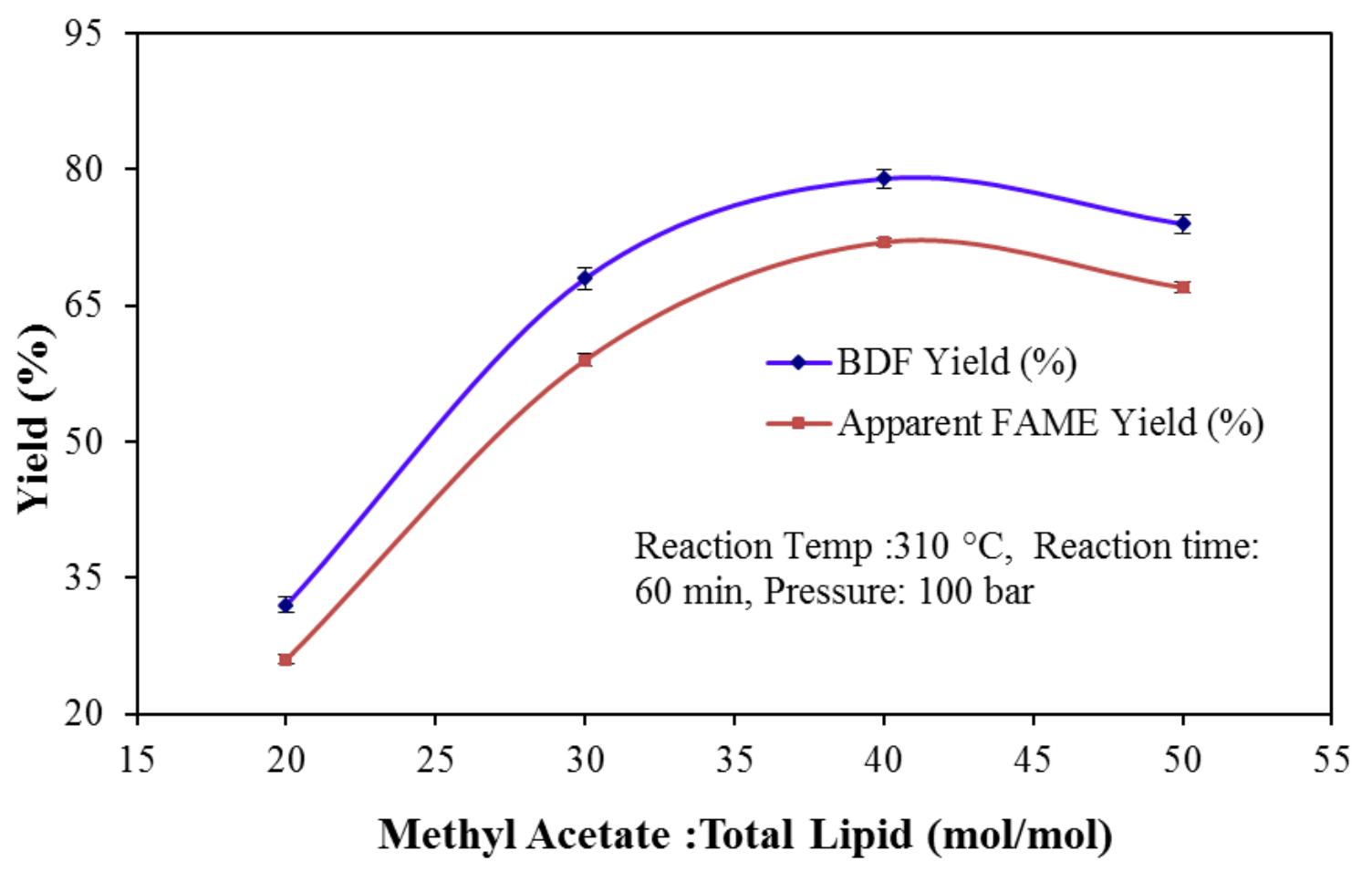

Fig. 3

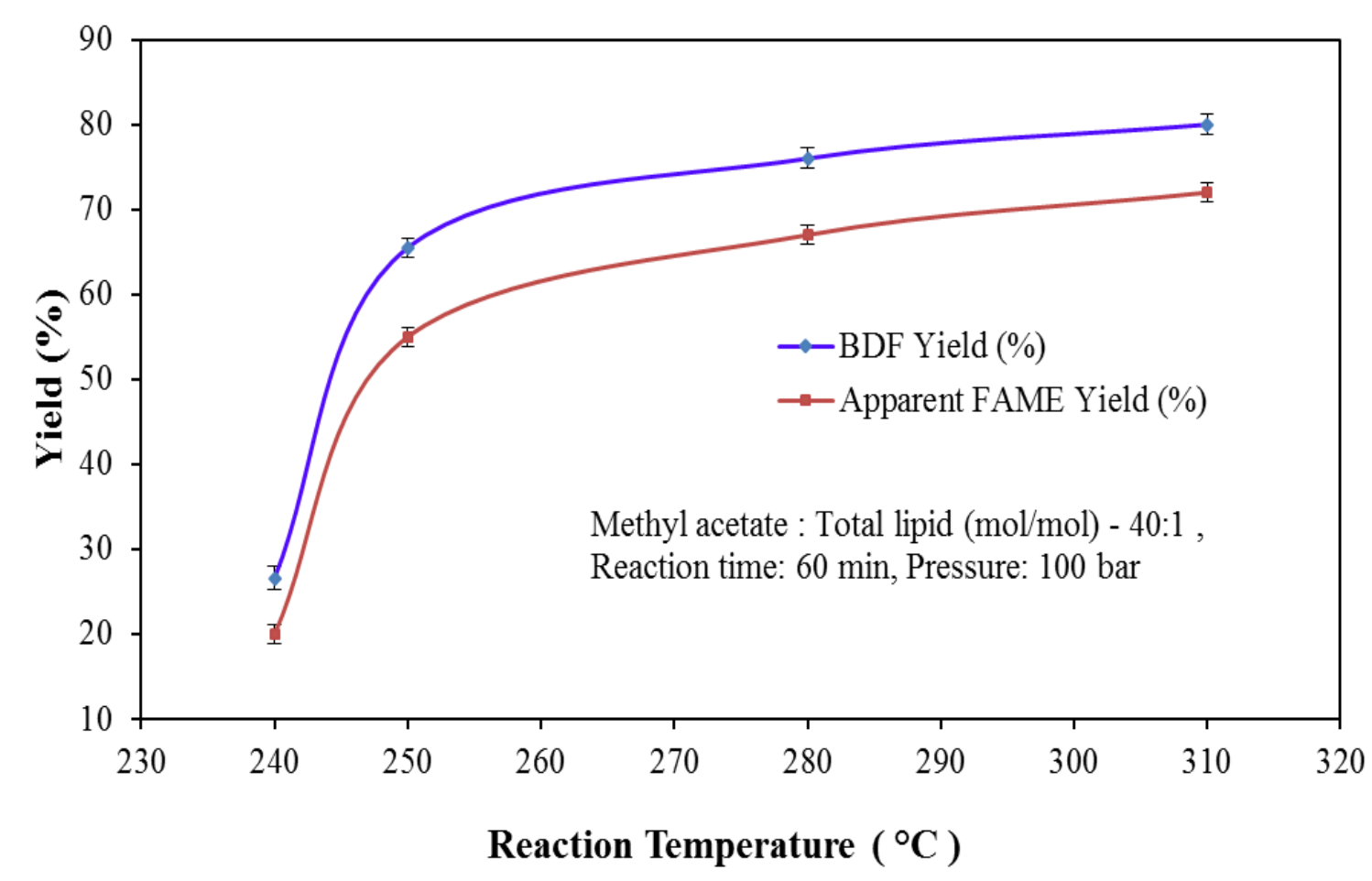


Fig. 4

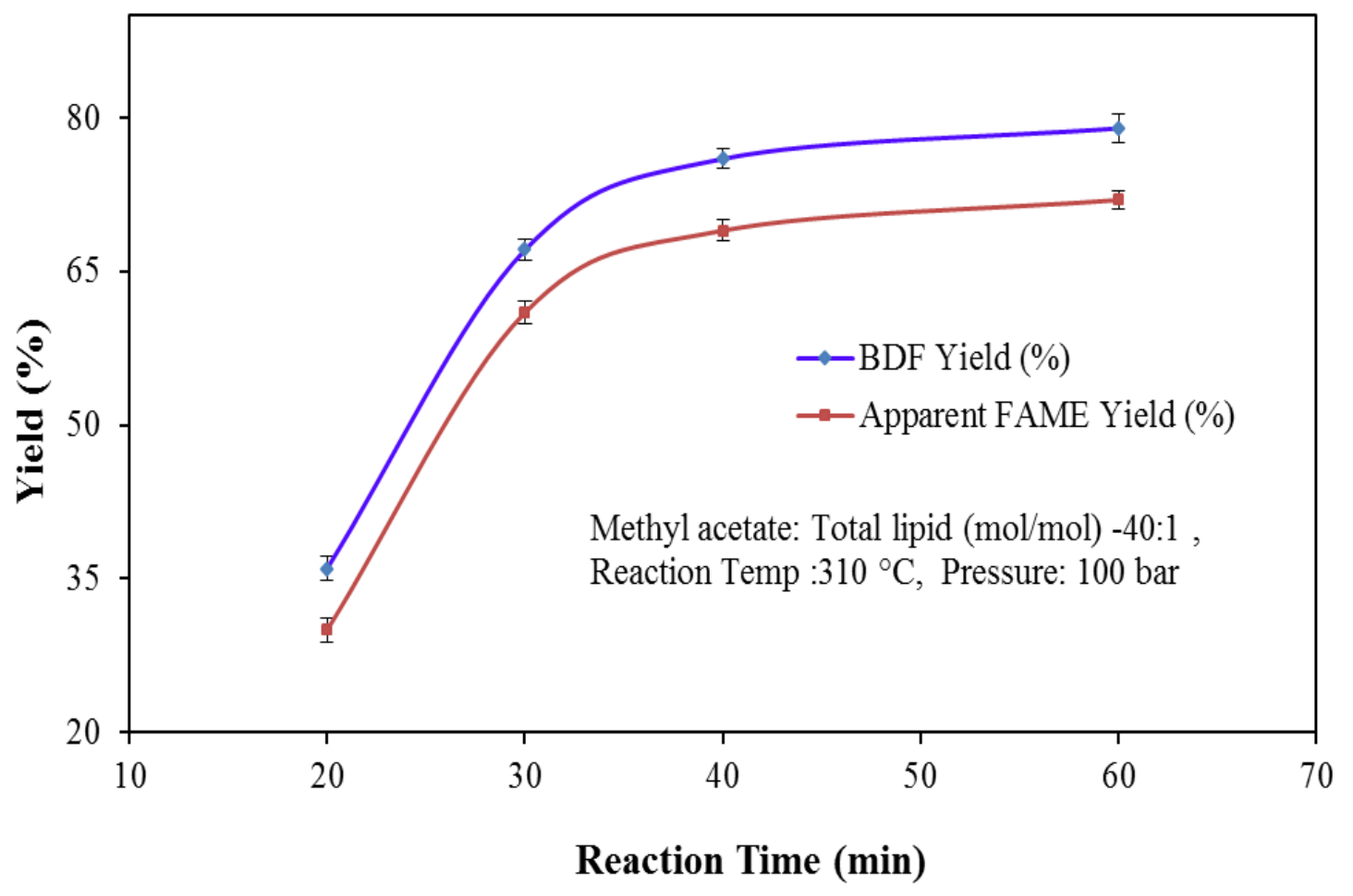

Fig. 5 


\section{List of Tables}

Table 1. The various absorption peaks of algal biodiesel fuel.

Table 2. The micro-elemental analysis (CHNOS) of total lipid and algal biodiesel fuel.

Table 3. Fuel properties of algal biodiesel fuel. 


\section{Table 1}

The various absorption peaks of algal biodiesel fuel.

\begin{tabular}{|c|c|c|c|}
\hline $\begin{array}{l}\text { Algal biodiesel fuel } \\
\text { wavenumber, } \mathrm{cm}-1\end{array}$ & $\begin{array}{l}\text { Group } \\
\text { attribution }\end{array}$ & Vibration type & $\begin{array}{l}\text { Absorption } \\
\text { intensity }\end{array}$ \\
\hline 3479.89 & $-\mathrm{OH}$ & stretching & Weak \\
\hline 3005.58 & $=\mathrm{CH}$ & stretching & Weak \\
\hline 2924.72 & $-\mathrm{CH}_{2}$ & $\begin{array}{l}\text { asymmetric } \\
\text { stretching vibration }\end{array}$ & Strong \\
\hline 2854.31 & $-\mathrm{CH}_{2}$ & $\begin{array}{l}\text { symmetric stretching } \\
\text { vibration }\end{array}$ & Strong \\
\hline 1745.90 & $-\mathrm{C}=\mathrm{O}$ & stretching & Strong \\
\hline 1464.43 & $-\mathrm{CH}_{3}$ & shear type vibration & Middling \\
\hline 1167.45 & $\mathrm{C}-\mathrm{O}$ & $\begin{array}{l}\text { symmetric stretching } \\
\text { vibration }\end{array}$ & Middling \\
\hline 1227.41 & $\mathrm{C}-\mathrm{O}$ & $\begin{array}{l}\text { symmetric stretching } \\
\text { vibration }\end{array}$ & Middling \\
\hline 968.09 & $\mathrm{C}-\mathrm{O}-\mathrm{C}$ & $\begin{array}{l}\text { anti-symmetric } \\
\text { stretching vibration }\end{array}$ & Weak \\
\hline
\end{tabular}

\section{Table 2}

The micro-elemental analysis (CHNOS) of total lipid and algal biodiesel fuel.

\begin{tabular}{cccc}
\hline & $\begin{array}{c}\mathrm{SC}^{-\mathrm{CO}_{2}} \\
\text { extracted total } \\
\text { lipid }\end{array}$ & $\begin{array}{c}\text { SCMA algal } \\
\text { biodiesel fuel } \\
\text { (BDF) }\end{array}$ & $\begin{array}{c}\text { ASTM testing } \\
\text { methods }\end{array}$ \\
\hline \% Carbon (C) & 75.09 & 75.34 & D5373 \\
\% Hydrogen (H) & 11.16 & 11.3 & D5373 \\
\% Nitrogen (N) & 0.46 & 0.05 & D5291 \\
\% Oxygen (O) & 12.99 & 13.28 & D5622 \\
\% Sulfur (S) & 0.09 & 0.02 & D1558 \\
\% Ash (A) & 0.21 & 0.166 & Difference \\
H/C & 1.8 & 1.84 & \\
O/C & 0.132 & 0.136 & \\
N/C & 0.005 & 0.0005 & \\
\hline
\end{tabular}




\section{Table 3}

Fuel properties of algal biodiesel fuel.

\begin{tabular}{ccccc}
\hline Fuel property & $\begin{array}{c}\text { SCMA algal } \\
\text { biodiesel fuel } \\
\text { (BDF) }\end{array}$ & Regular diesel & $\begin{array}{c}\text { US ASTM D6751 } \\
\text { biodiesel standard }\end{array}$ & Testing methods \\
\hline Specific gravity & $0.84-0.86$ & 0.85 & $0.86-0.9$ & ASTM D 287 \\
$\begin{array}{c}\text { Kinematic viscosity } \\
\left(\mathrm{mm}^{2} / \mathrm{s}\right)\end{array}$ & $4.5-4.8$ & 2.6 & $1.9-6.0$ & ASTM D 445 \\
$\begin{array}{c}\text { Higher heating value } \\
(\mathrm{MJ} / \mathrm{kg})\end{array}$ & 39.2 & 42 & ---- & Dulong's (BDF) \\
$\begin{array}{c}\text { Pour point }\left({ }^{\circ} \mathrm{C}\right) \\
\text { Cetane number }\end{array}$ & -11 to -8 & -20 & -15 to 10 & ASTM D240 (Diesel) \\
& $52-55$ & 46 & 47 min & ASTM D 97 \\
\hline
\end{tabular}


Graphical Abstract (for review)

\section{Graphical Table of Content}

"Biodiesel fuel production from algal lipids using supercritical methyl acetate (glycerin-free technology)" by Patil et al.

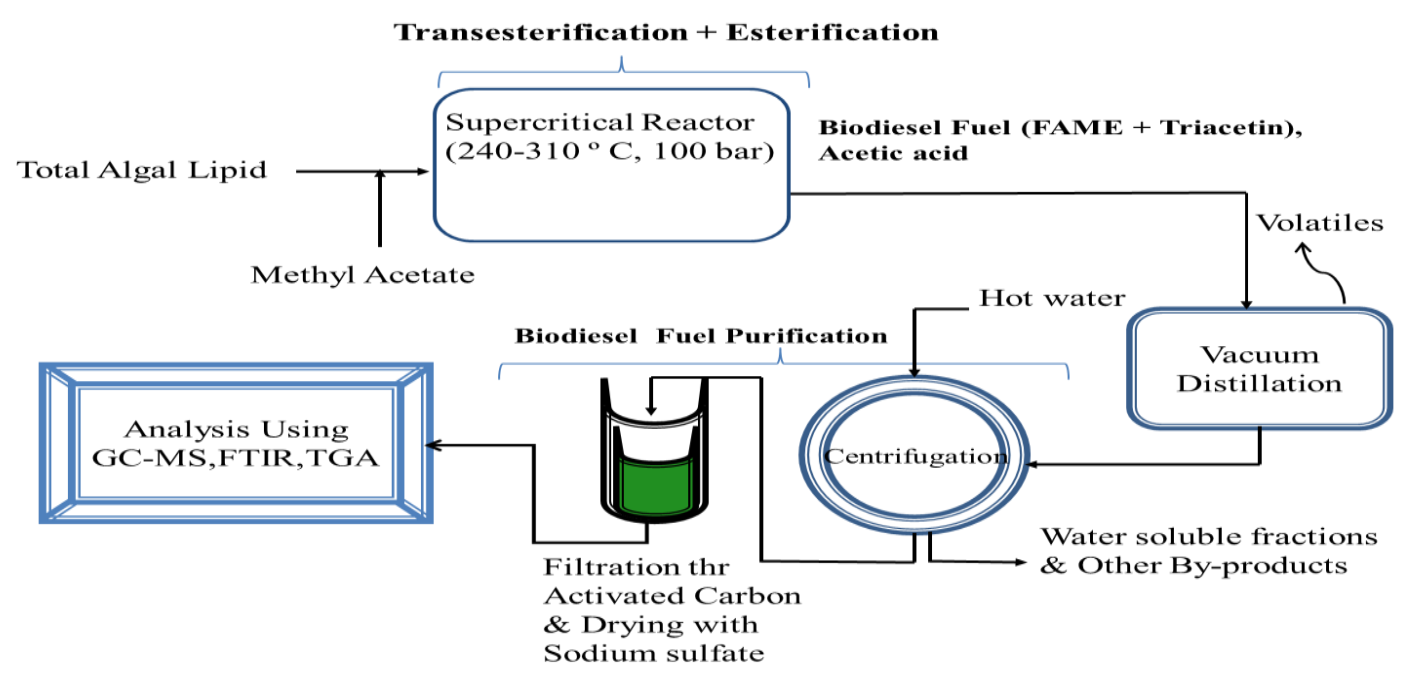

